\title{
Pd-Fe Nanoparticles as Electrocatalysts for Oxygen Reduction
}

\author{
SUPPORTING INFORMATION \\ Min-Hua Shao, Kotaro Sasaki, Radoslav R. Adzic \\ Chemistry Department, Brookhaven National Laboratory, Upton, NY 11973
}

\section{Experimental procedures}

Four samples with a molar ratio of Pd:Fe from 1:1 to 4:1 were prepared. 19 wt \% carbon supported Pd nanoparticles $(\mathrm{Pd} / \mathrm{C})$ obtained from ETEK and $\mathrm{FeCl}_{3}$ (Aldrich) solution were mixed and sonicated for 30 minutes, then dried at $80^{\circ} \mathrm{C}$. The mixture was heated at $500^{\circ} \mathrm{C}$ in $\mathrm{H}_{2}$ for 2.5 hours. For comparison, one sample of $\mathrm{Pd} / \mathrm{C}$ was heated under the same conditions to obtain similar particle size. Another sample with Pd:Fe of 3:1 was prepared by heating the mixture of carbon particles (Vulcan XC-72), $\mathrm{PdCl}_{2}$ (Alfa Aesar) and $\mathrm{FeCl}_{3}$ salts under the same conditions.

Thin film electrodes with electrocatalysts were prepared by placing $10 \mu \mathrm{l}$ of the nanoparticle suspension $\left(0.2 \mathrm{mg}_{\mathrm{Pd}} \mathrm{ml}^{-1}\right)$ onto a glassy carbon electrode (5-mm diameter). The Pd loading of each sample was $10 \mu \mathrm{g} \mathrm{cm}^{-2}$. After drying in air, the electrode was covered by $5 \mu$ of a dilute Nafion ${ }^{\circledR}$ solution. Electrolytes were prepared from Optima ${ }^{*}$ sulfuric acid and perchloric acid obtained from Fisher and UV-plus water (Millipore). An $\mathrm{Ag} / \mathrm{AgCl}, \mathrm{Cl}^{-}$electrode and a Pt flag were used as the reference and counter electrode, respectively. All the electrochemical measurements were carried out at room temperature.

The kinetic currents were calculated based on eq. 1:

$$
\frac{1}{j}=\frac{1}{j_{k}}+\frac{1}{j_{d}}
$$

Where $j$ and $j_{\mathrm{d}}$ are the measured current and limited current, respectively.

Powder x-ray diffraction patterns (XRD) were taken by a commercial diffractometer (Phillips 3100) using Cu Ka radiation (1.54056 ̊̊). Samples for analyses were obtained by loading the slurries onto a glass slide, followed by drying in air. Diffraction patterns were collected from 20 to $80^{\circ}$ at a scanning rate of $0.6^{\circ}$ per minute with a step size of $0.02^{\circ}$. 


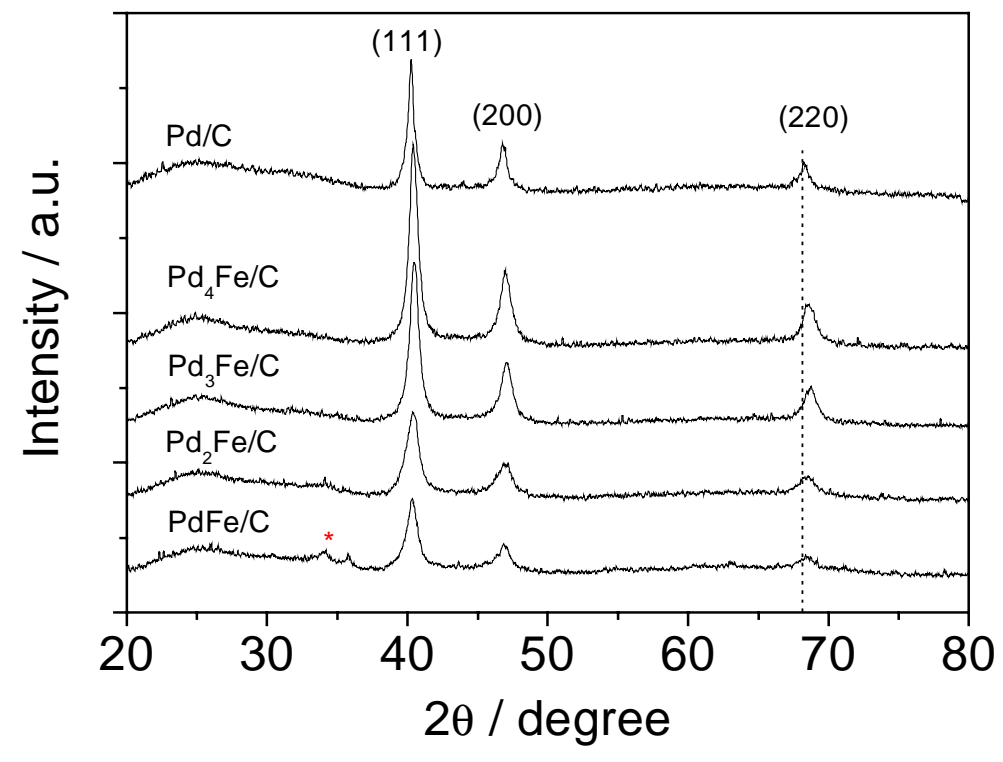

Figure S1. X-ray diffraction pattern of Pd/C (ETEK) and Pd-Fe/C alloys using $\mathrm{Cu}$ $\mathrm{K}_{\alpha}$ radiation. All samples were treated at $500{ }^{\circ} \mathrm{C}$. The dotted line and $*$ indicate the standard $2 \theta$ value of Pd at (220) and the superlattice reflection of the ordered PdFe phase, respectively. 


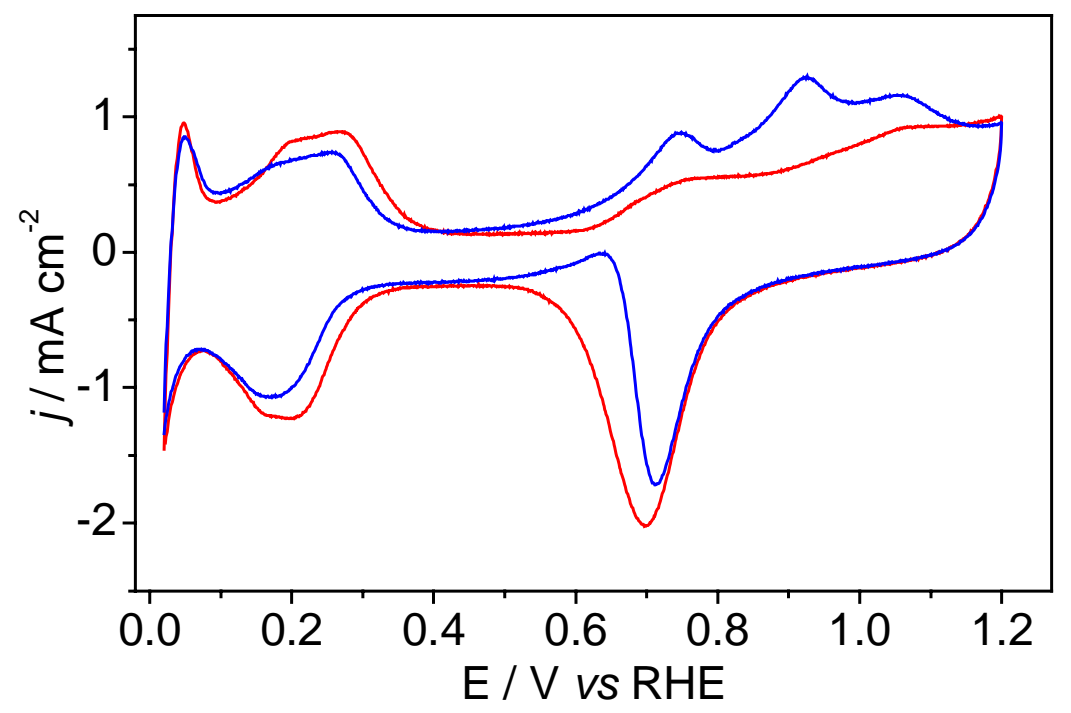

Figure $\mathrm{S} 2$. Cyclic voltammograms of $\mathrm{Pd}_{3} \mathrm{Fe} / \mathrm{C}$ in nitrogen saturated $0.1 \mathrm{M} \mathrm{HClO}_{4}$ solution with (blue line) and without (red line) $0.1 \mathrm{M}$ Methanol. Sweep rate $50 \mathrm{mV} \mathrm{s}^{-1}$; Pd loading $18 \mu \mathrm{g} \mathrm{cm}^{-2}$. 


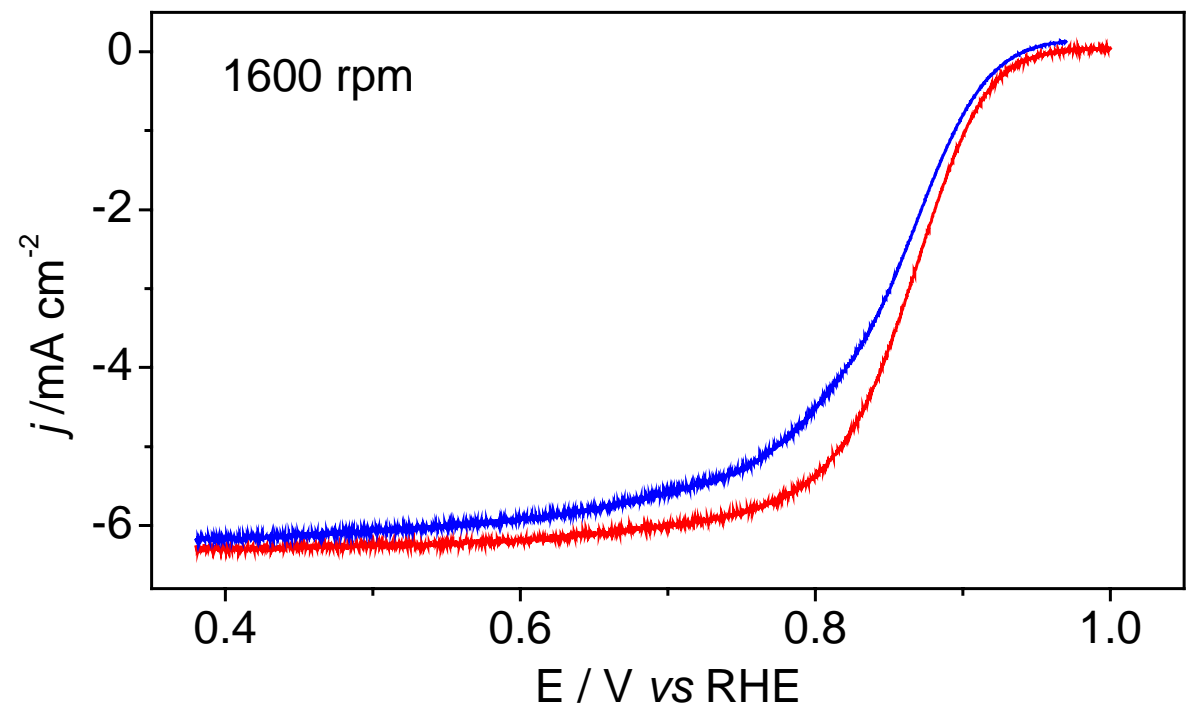

Figure S3. Comparison of polarization curves for the ORR on $\mathrm{Pd}_{3} \mathrm{Fe} / \mathrm{C}$ nanoparticles in $0.1 \mathrm{M} \mathrm{HClO}_{4}$ with (blue line) and without (red line) $0.1 \mathrm{M}$ Methanol. Sweep rate $10 \mathrm{mV} \mathrm{s}^{-1}$; room temperature; Pd loading $18 \mu \mathrm{g} \mathrm{cm}^{-2}$. 